\title{
La justicia restaurativa en el Derecho Internacional Público y su relación con la justicia transicional
}

\author{
Restorative justice in Public International Law and its relation to \\ transitional justice
}

https://doi.org/10.15332/iust.v0i15.2084

\section{María del Refugio Macías Sandoval}

Doctora en Derecho por la Universidad Autónoma de Baja California (UABC), México; profesora investigadora de carrera de la Facultad de Derecho Tijuana, UABC; responsable del Cuerpo Académico "Justicia Alternativa y Social", y miembro de la Asociación Internacional de Doctores en Métodos Alternos de Solución de Conflictos.

Correo electrónico: mmacias@uabc.edu.mx

\section{Gloria Puente Ochoa}

Doctora en Derecho por la Universidad Autónoma de Baja California (UABC), México; profesora investigadora de carrera de la Facultad de Derecho Tijuana, UABC; miembro del Sistema Nacional de Investigadores, nivel I del Cuerpo Académica "Justicia Alternativa y Social, y de la Asociación Internacional de Doctores en Métodos Alternos de Solución de Conflictos.

Correoelectrónico: gpuente@uabc.edu.mx

\section{Isaac de Paz González}

Doctor en Derechos Fundamentales y Libertades Públicas por la Universidad Castilla-La Mancha España; profesorinvestigador de tiempo completo de la Universidad Autónoma de Baja California, Facultad de Derecho Tijuana, miembro de The Society of Legal Scholars, y del Sistema Nacional de Investigadores.

Correo electrónico: isaac.depaz@uabc.edu.mx

\section{Resumen}

La justicia restaurativa es una filosofía y un método para arreglar conflictos que han perturbado la paz, con el fin de restablecerla a través de un proceso en el que intervengan directamente los involucrados: víctima, victimario y comunidad.

Su aplicación en los conflictos cotidianos con resultados exitosos la ha posicionado en el ámbito internacional y ahora es recomendada en instrumentos de derecho internacional público para alcanzar la armonía perdida por conflictos derivados de hechos considerados delitos de derecho internacional público.

Una aplicación específica es en la llamada justicia transicional, como un método para restablecer la paz sin afectar a las víctimas ni favorecer la impunidad, proceso que hoy está viviendo Colombia.

Palabras clave: Justicia restaurativa, justicia transicional, proceso de paz, principios de derecho internacional. 
Abstract

Restorative justice is a philosophy and method for settling conflicts that have disturbed peace, in order to restore it through a process involving directly the victims, victimizer and community.

Its application in daily conflicts with successful results has positioned it in the international arena and is now recommended in instruments of public international law to achieve the harmony lost by conflicts derived from facts considered crimes of public international law.

A specific application is in the so-called transitional justice, as a method to restore peace without affecting the victims or favoring impunity, a process that Colombia is experiencing today.

Keywords: Restorative justice, transitional justice, peace process, principles of international law.

\section{Résumé}

La justice réparatrice est une philosophie et une méthode pour régler les conflits qui ont troublé la paix, afin de la restaurer à travers un processus dans lequel les personnes impliquées interviennent directement: victime, agresseur et communauté.

Son application dans les conflits quotidiens avec des résultats réussis l'a positionné au niveau international et est maintenant recommandé dans les instruments de droit international public pour réaliser l'harmonie perdue en raison des conflits découlant d'actes considérés comme des crimes de droit international public.

Une application spécifique est dans la soi-disant justice transitionnelle, comme une méthode pour rétablir la paix sans affecter les victimes ou favoriser l'impunité, un processus que la Colombie connaît actuellement.

Mots-clés: Justice réparatrice, justice transitionnelle, processus de paix, principes du droit international. 


\title{
La justicia restaurativa en el Derecho Internacional Público y su relación con la justicia transicional ${ }^{*}$
}

\author{
María del Refugio Macias Sandoval \\ Gloria Puente Ochoa \\ Isaac de Paz González
}

\section{INTRODUCCIÓN}

En este trabajo se trata a la justicia restaurativa en cuanto a sus características definitorias, su trascendencia en la solución de conflictos que interesan al derecho internacional público, y en específico, su papel relevante en los procesos para transitar de un estado de violencia al restablecimiento de la paz, es decir, lo que hoy se llama justicia transicional, como la que se vive hoy en Colombia.

En líneas generales, la justicia restaurativa es un medio de solución de controversias extrajudicial, que consiste en la participación de los actores del conflicto para que ellos mismos lleguen a acuerdos que le pongan fin y gestionen las consecuencias del hecho dañoso, de tal manera que se repare el daño a la víctima, se reinserte al ofensor a su comunidad y pueda llevar una vida en armonía con los demás, sin repetir el hecho dañoso. En este proceso intervienen los directamente implicados en el conflicto, quienes toman decisiones para resolverlo de acuerdo con sus necesidades, guiados por un profesional, con apego a ciertos principios ya adoptados por el derecho internacional.

El enfoque de derecho internacional público se debe a que la justicia restaurativa, de haberse originado en el ámbito del derecho común, ha trascendido de tal manera que existen organismos y documentos que se ocupan de difundirla para resolver conflictos originados por delitos calificados de derecho internacional público: el genocidio; los crímenes de guerra, de lesa humanidad y de agresión. Los métodos y las estrategias de la justicia restaurativa aplicados en los conflictos derivados de

* Este artículo es resultado de los proyectos de investigación: "La aplicación de la justicia restaurativa para la reparación del daño y la prevención del delito" y "Mediación penal y justicia restaurativa", ambos financiados, el primero por la Universidad Autónoma de Baja California, y el segundo por fondos federales del Programa para el Desarrollo Profesional Docente (PRODEP), como parte de la Red Temática Métodos Alternos de Solución de Conflictos, integrada por cinco cuerpos académicos de diversas universidades mexicanas y por grupos de investigación de otras universidades del extranjero. 
estos delitos se distancian de los tradicionalmente practicados, puesto que el derecho penal se ha enfocado en el hecho y en su autor, olvidando a la víctima, a quien, por lo general, se ha marginado sin poner atención en la reparación del daño.

Con el surgimiento de la victimología, se centró la atención en la víctima y en la justicia restaurativa como soporte filosófico y método práctico para satisfacer la reparación del daño, según las necesidades concretas de la víctima, expresadas por ella misma, sin que esto signifique sustitución del derecho penal, ni descuido del victimario. Es un método inclusivo que por su efectividad se recomienda para resolver los conflictos donde quiera que se presenten.

La justicia restaurativa cumple un papel específico y relevante para poner fin a un conflicto y alcanzar una paz duradera en los procesos de justicia transicional, tanto en el momento de llegar a acuerdos como a la hora de hacerlos efectivos. Se analiza el caso Colombia, que vive en estos momentos un proceso de paz que le anteceden más de 52 años de guerra entre el Gobierno y las Fuerzas Armadas Revolucionarias de Colombia-Ejército del Pueblo (FARC-EP) con incontables víctimas.

\section{ANTECEDENTES DE LA JUSTICIA RESTAURATIVA}

La justicia restaurativa ha sido uno de los procedimientos más antiguos para resolver conflictos, sobre todo en las comunidades indígenas, pero de manera formal, comenta Aída Kelmelmajer (2004), se puede considerar su origen en la decisión de una Corte canadiense, en Kitchener, Ontario, que ordenó a ciertos jóvenes, causantes de daños a las propiedades de algunos vecinos, que acordaran con ellos la manera de reparar a su satisfacción. Esta medida resultó exitosa al grado de dar lugar a la creación del Programa de Reconciliación entre Víctimas y Ofensores.

En Indiana, siguiendo el modelo de Ontario, se creó una organización no lucrativa: Centro para Justicia Comunitaria. En nueva Zelanda se celebraron reuniones restaurativas para niños, jóvenes y sus familias. Las familias de los ofensores y de las víctimas participaron en la imposición de la sanción al ofensor que incluía la reparación del daño a la víctima, después de llegar a un acuerdo con ella y con miembros de la comunidad.

Uno de los precursores de la justicia restaurativa fue Albert Eglash (1958a), psicólogo norteamericano que propuso un sistema alternativo que llamó Creative Restitution; consistía en que "an offender, under appropriate supervision, is helped to find some way to make amends to those he has hurt by his offense, and to 'walk a second mile' by helping other offenders" (p. 20).

Las propuestas doctrinales más relevantes que dieron origen a una concepción restaurativa de la justicia las encontramos en dos artículos: uno de Randy Barnett (1977), que propone la restauración como un nuevo paradigma de la justicia criminal; el otro es de Nils Christie (1977) quien afirma que el Estado se ha apropiado del conflicto que le corresponde a los ciudadanos, puesto que el conflicto es parte de la vida social y, por tanto, no debe delegarse a otros que no sean los involucrados. 
Por otra parte, la insistencia desde la victimología en recurrir a los medios alternativos de solución de controversias influyó también en el avance de la justicia restaurativa, pues esta filosofía enlaza muy bien con la atención a la víctima, al incluirla como protagonista de los procesos de diálogo, con la participación del victimario (Beristain, 1996). Una de las características de la justicia restaurativa es que la víctima interviene directamente para manifestar cómo fue afectada por el delito y cuáles son sus necesidades de reparación.

Comenta J. Llobet (2011) que los proyectos de justicia restaurativa se han extendido a diversos países: Canadá, Reino Unido, Nueva Zelanda, Bélgica, Francia, Italia, Finlandia, Noruega, Alemania, Austria, Japón, Brasil, Sudáfrica, Australia, y que a mediados de los noventa ya existían más de mil programas funcionando en América del Norte y en Europa.

Han aparecido numerosas publicaciones y documentos internacionales con lineamientos para su aplicación, como la Recomendación de la ONU del 29 de noviembre de 1987: Declaración sobre los Principios Fundamentales de Justicia para las Victimas de Delitos y del Abuso del Poder, y organismos difusores y aplicadores de esta filosofía restauradora, lo que le da a la justicia restaurativa el carácter de internacional.

\section{CARACTERIZACIÓN DE JUSTICIA RESTAURATIVA}

El 1993, en el Congreso Internacional de Budapest se fijó el nombre de Justicia Restaurativa, de entre otras variantes de adjetivos: pacificadora, transformadora, comunitaria, reparativa, reparadora, restitutiva, reintegradora o reintegrativa.

La justicia restaurativa se caracteriza por ser un proceso en el que intervienen las partes interesadas en manejar las consecuencias del delito en el presente y para el futuro, de manera equitativa. El principal objetivo de este nuevo modelo es reparar el daño, prevenir la repetición de la conducta dañosa, es decir, restaurar la paz al resolver un conflicto por vías no violentas.

Este proceso puede prolongarse, pues como prescribe el Manual sobre programas de justicia restaurativa de las Naciones Unidas (2006), algunos casos implican delitos muy serios que requieren preparaciones extensas antes de un encuentro cara a cara; estos preparativos para una sesión restaurativa entre el delincuente y la víctima pueden abarcar varios años, porque un proceso restaurativo significa una solución profunda, cuyas consecuencias impacten en el mejoramiento de las relaciones sociales a través de la reparación del daño, la promesa de no repetición y el eventual perdón de la víctima al ofensor.

El manual sobre programas de justicia restaurativa citado sugiere las metodologías restaurativas, los principios básicos que deben regir a estos programas, los lineamientos y la dinámica de intervención, puesto que debe ser un proceso guiado por un profesional, quien interviene para facilitar la participación de los directamente involucrados en el conflicto, que se trata de resolver o encauzar; no basta llegar a 
acuerdos, sino que estos han de ser equitativos, libres de presiones, resultado de un diálogo en un ambiente tranquilo en el que cada quien sienta que ha sido escuchado y, sobre todo, que se satisfaga a la víctima y que se propicie la recuperación del ofensor para que pueda integrarse a una vida normal en su comunidad, sin que repita su conducta agresiva.

Howard Zehr (2006), iniciador de la justicia restaurativa moderna, delimita sus características y sienta sus principios. Afirma que se basa en tres preguntas principales que contrastan con la justicia del derecho penal: a) quién ha sido dañado, en lugar de qué leyes se violaron; b) cuáles son las necesidades de la víctima, en lugar de quién lo hizo; c) quién tiene la responsabilidad de atender estas necesidades, en lugar de qué castigo merece el ofensor.

Ha sustentado la justicia restaurativa en algunos principios:

1. Devolver el papel protagónico a la víctima y al ofensor para llegar juntos a una solución.

2. Dar oportunidad al ofensor de asumir la responsabilidad sobre el hecho cometido.

3. Hacer participar a la comunidad para hacer que la reparación no solo sea un fin individual del ofensor con respecto a la víctima, sino también un fenómeno que busca la paz social. Por ello, la participación de la comunidad es fundamental para el cumplimiento de los acuerdos.

Estos principios son aplicables a todos los ámbitos donde exista un conflicto, pero la necesidad de volver las cosas al estado en que estaban, de reparar y restaurar el daño a las víctimas, de reintegrar al ofensor a la sociedad, de garantizar la no repetición, se hace más imperiosa cuando se habla de delito.

La reparación penal no se debe confundir con la restitución o indemnización civil a las víctimas, sino que la primera va más allá de una indemnización pecuniaria, porque debe satisfacer el interés de la víctima, que no siempre se reduce a la satisfacción material, esta podría ser simbólica, como reconocer la culpabilidad, dar muestras de arrepentimiento, pedir perdón o hacer algo en favor de la víctima o sus familiares.

Ness y Heetderks (2015) afirman que la justicia restaurativa descansa en cuatro ejes: inclusión, encuentro, reparación del daño y reinserción. La inclusión se refiere a la participación de los involucrados en el conflicto en un proceso de diálogo en el que se reconozcan los intereses de cada uno y voluntariamente lleguen a acuerdos; el encuentro significa el acercamiento de los involucrados en el conflicto: ofensor, ofendido y comunidad, que a través de reuniones se dé la comunicación dialógica para llegar a acuerdos favorables a los intereses de cada quien; la reparación del daño implica que el ofensor acepte su culpa, esté dispuesto a resarcir el daño y a no repetir la conducta ofensiva, con esto se da a la víctima la posibilidad de trascender su posición de víctima para que recupere la dignidad humana, ejerza sus derechos y sea capaz de transformar las situaciones de inequidad que la han puesto en ese lugar (Britto, 
2010, p. 21); y la reinserción se orienta hacia la consideración de la dignidad humana del ofensor, a pesar de su conducta dañosa, a que se le asista profesionalmente, tanto material como moral, para que pueda reinsertarse en su comunidad y reinicie una vida normal y armónica con los de su entorno.

La justicia restaurativa, en general, se considera uno de los medios alternativos de solución de controversias, junto con la mediación, la conciliación, la negociación, entre otros. Se asemeja a todos ellos en cuanto que la solución se busca por la vía no judicial, y a través de un arreglo pacífico con intervención de un profesional y guiado por los principios de voluntariedad, confidencialidad, imparcialidad, neutralidad, equidad, flexibilidad y honestidad. Pero también, la justicia restaurativa es una filosofía que inspira todos los esfuerzos por restablecer la paz social allí donde ha sido perturbada por hechos violentos o agresores de la armonía social; en este sentido, la justicia restaurativa es ese conjunto de principios que guían cualquier proceso pacífico por el que los beligerantes, o los ofensores y víctimas constituyen acuerdos que den por terminados los hechos violentos originadores de los conflictos, y vuelvan las cosas al estado en que estaban después de haber satisfecho las necesidades de reparación y reinserción social.

La voluntariedad se refiere a que las partes son las únicas facultadas para iniciar, permanecer o retirarse de un procedimiento alternativo, sin ninguna presión, y son ellas las únicas que por su libre voluntad pueden llegar a acuerdos, guiados por un profesional en cuanto a la legalidad de la resolución. La confidencialidad impone el deber de los participantes: las partes en conflicto y el profesional que interviene, de guardar reserva de las informaciones vertidas en cualquiera de las sesiones que componen estos procesos. Aunque esta norma de confidencialidad tiene excepciones, como en el caso de que se descubra la intención de cometer algún delito que pueda traer graves perjuicios a otras personas.

La imparcialidad impide que el profesional que guía las sesiones se incline por alguna de las partes, o que sus comentarios parezcan favorecer a alguna de ellas.

La neutralidad significa que el profesional no debe guiarse por su punto de vista ni por su forma de pensar, ni hacer comentarios que induzcan a las partes a tomar decisiones en un sentido, sino que ellas sean las que libremente decidan en un marco de legalidad y equidad.

La equidad exige que haya igualdad entre las partes, no puede haber equidad si la relación entre ellas es de poder, donde uno es el jefe y otro el subordinado. El profesional interviniente debe cerciorarse que ambos están en igualdad de condiciones, con libertad de expresarse sin temor a represalias, o a sufrir consecuencias por lo manifestado ahí. Para Peña González (2010), la equidad es el sentido de la justicia aplicada al caso particular.

La honestidad tiene relación con el principio de buena fe; las partes deben proceder en forma transparente en el proceso, significa que lo que ahí se manifiesta corresponde a la verdad, sin crear falsas expectativas. 
La flexibilidad evita la rigidez del proceso tradicional para responder a las necesidades de las partes. Estos principios constituyen reglas mínimas para lograr un acuerdo eficaz y satisfactorio para los actores del conflicto. Pero la justicia restaurativa se distingue de los otros medios, sobre todo, en cuanto al fin, porque no concluye con un acuerdo que arregle un conflicto, sino que el fin es que después del conflicto, las relaciones se restablezcan; la víctima se sienta satisfecha porque se hizo lo posible por reparar el daño, no solo material, sino moral, con las consecuencias que se derivan; y el ofensor puede reintegrarse a su círculo social con la seguridad de que no repetirá el hecho dañoso. Entonces la justicia restaurativa no solo es un medio, sino un fin: restaurar la armonía social rota por un hecho grave que puede constituir un delito, por lo que los procesos restaurativos pueden ser de larga duración.

Estos principios son comunes a cualquier medio alternativo de solución de controversias. La diferencia entre la justicia restaurativa y los demás medios es que los procesos restaurativos son duraderos y se enfocan en la solución profunda del desajuste social que produjo un conflicto; por su propia naturaleza, son procesos largos, que no terminan con un acuerdo de reparación o con el pago de los daños sin tener en cuenta cómo se integran a la sociedad, tanto la víctima como el victimario.

\section{LA JUSTICIA RESTAURATIVA EN DELITOS DE DERECHO INTERNACIONAL PÚBLICO}

La justicia restaurativa nació en el contexto de las relaciones cotidianas para resolver los conflictos que surgen a diario, y ha sido aplicada con gran éxito como respuesta al crimen, con el objeto de orientar la atención hacia la víctima: reconocer su sufrimiento y reparar el daño; se busca, más que castigar al ofensor, intentar reincorporarlo a la comunidad "con el fin de restablecer los lazos sociales" (Uprimny, 2006, p. 119). En este proceso, es necesaria la participación voluntaria de los involucrados: víctima, ofensor y comunidad, guiados por un facilitador profesional, en un marco de flexibilidad y acompañamiento, tutelados por el Estado a través de instituciones especializadas; el Estado deja su papel protagónico y lo devuelve a los directamente implicados. Ellos, de común acuerdo, deciden manejar las consecuencias del delito de forma que se satisfagan las necesidades, tanto de la víctima y de la comunidad como del delincuente u ofensor, y así se restaure el tejido social en forma duradera. De este modo, la víctima tiene acceso a la justicia y el delincuente se reintegra otra vez a su comunidad con el propósito de no volver a delinquir.

Los resultados de la aplicación de la justicia restaurativa en el contexto ordinario han llamado la atención de la comunidad internacional, la que en diversos documentos se ha referido a ella y ha recomendado su aplicación, sin favorecer la impunidad,

de ello igualmente deriva la responsabilidad penal del dirigente o de altos mandos de estructuras jerárquicas en virtud de un aparato organizado de poder, donde tal responsabilidad implica la consecución de requisitos como 
la existencia de una relación entre superior y subordinado; el conocimiento del superior de los hechos que implican la comisión de crímenes; y el de la omisión del superior de tomar decisiones encaminadas a evitar la comisión de tales crímenes, teniendo conocimiento de ello (Huertas \& Amaya, 2016).

Aun en los casos de violaciones graves de derechos humanos por grupos armados o gobiernos dictatoriales, pues el conflicto es connatural al ser humano y las estrategias que han mostrado ser efectivas para resolverlo habrá que aplicarlas dondequiera que este se presente, atendiendo siempre las particularidades del caso, pues quienes están involucrados son personas concretas, con sus propias necesidades que requieren atención, especialmente las víctimas, a quienes internacionalmente se les han reconocido sus derechos; a ellas se refiere ampliamente la obra de Irving Waller (2013), quien pone al descubierto el enfoque de la atención en los delincuentes en perjuicio de los derechos de las víctimas, y cómo ha evolucionado el proceso de reconocimiento de los derechos de estas hasta constituir un movimiento que ha dado origen a la victimología, y que según Cuarezma (1996) se ha consolidado a partir de 1973 con el Primer Simposio Internacional de Victimología. Estos simposios se han celebrado cada tres años, el último, en 2015, en Perth Australia. La dimensión que ha alcanzado esta disciplina ha influido en el rápido desarrollo de programas de justicia restaurativa que reúnen en el mismo plano de atención a las partes del conflicto.

Por esta razón, partiendo de lo ordinario, delimitado territorialmente, la justicia restaurativa puede transitar a todos los contextos en donde haya un conflicto entre seres humanos.

Así, en poco tiempo, los métodos y estrategias de la justicia restaurativa transcendieron hasta la comunidad internacional y empezó a promoverse este modo alternativo de acceso a la justicia; documentos internacionales la recomiendan como uno de los medios para resolver conflictos y restablecer la armonía quebrantada por desórdenes sociales. Esta filosofía caló en lo profundo y pronto se extendió más allá de lo cotidiano, en escenarios internacionales: congresos, programas, documentos de organismos internacionales como la Declaración del Consejo Económico y Social de las Naciones Unidas (2002) que define la justicia restaurativa como una respuesta evolucionada al delito, "que respeta la dignidad y la igualdad de todas las personas, favorece el entendimiento y promueve la armonía social mediante la recuperación de las víctimas, los delincuentes y las comunidades" y el Manual sobre programas de justicia restaurativa (ONU, 2006), que califica a la justicia restaurativa como un instrumento "para apoyar a los países en la implementación de leyes y en el desarrollo de reformas en materia de derecho penal... Este enfoque está dentro de una serie de medidas y programas inspirados por los valores de la justicia restaurativa". Como se ve, la comunidad internacional se interesa en que se resuelvan los conflictos pacíficamente, en donde quiera que se den y en cualquier dimensión que se presenten.

El interrogante es si es susceptible de aplicar la justicia restaurativa en delitos graves, aquellos que afectan la vida de las personas y que ocasionan un daño irreparable, incluso crímenes de derecho internacional, aquellos de carácter sistemático y masivo, 
como los delitos de Estado, que afectan a la esencia del ser humano; o los crímenes de guerra, de lesa humanidad, de genocidio, de agresión, que son de la competencia de la Corte Penal Internacional. Son delitos que trascienden a las víctimas; en estos casos se reclama que se atiendan los requerimientos de justicia de las víctimas, antes que proponer cualquier tipo de intervención conciliatoria o restaurativa, porque hay asimetría entre víctimas y victimarios, que impide cualquier acercamiento dialógico, que solo se da entre iguales. No es posible admitir concesiones, sin que antes exista un proceso para conocer la verdad y se hayan tomado soluciones según el derecho penal.

Un delito internacional es aquel definido como tal por el Derecho Internacional Público. Sobre los delitos internacionales, la jurisdicción es universal, es decir, los presuntos responsables de la comisión de uno de estos delitos pueden ser juzgados por cualquiera de los Estados de la comunidad internacional, independientemente de su nacionalidad y del lugar en que se hayan cometido; son violaciones graves a las normas del derecho internacional imperativo (ius cogens); no son, por lo mismo, prescriptibles, y no admiten amnistía ni indulto.

Cualquier propuesta de enfoque restaurativo para resolver un conflicto derivado de un delito internacional debe estar precedido por un proceso de búsqueda de la verdad. Sin embargo, la justicia restaurativa está cumpliendo un papel importante en los procesos de reconciliación nacional, llamados de justicia transicional, es decir, cuando se quiere transitar hacia la paz y dejar atrás un contexto de violencia extrema que afecta a grandes masas de población.

\section{LA JUSTICIA RESTAURATIVA EN LOS INSTRUMENTOS INTERNACIONALES}

Las amargas experiencias de las guerras mundiales y de los conflictos violentos que ha padecido la humanidad han movilizado a los gobiernos locales y a la comunidad internacional, para buscar maneras de evitar que se repitan estos sucesos y de atenuar, en lo posible, las consecuencias de sufrimiento para las víctimas, a quienes se les han reconocido sus derechos en instrumentos internacionales y se ha instado a los gobiernos a que

Adopten medidas ... a fin de garantizar el reconocimiento y el respeto universal y efectivo de los derechos de las víctimas de delitos y del abuso de poder... [y] utilizar mecanismos para la solución de controversias que faciliten la conciliación y la reparación del daño (Naciones Unidas, 1985).

Un documento de gran trascendencia como marco referencial para la justicia restaurativa es la Declaración y el Programa de Acción de Viena (DPAV), aprobado por la Conferencia Mundial de Derechos Humanos (CMDH) celebrada en Viena en 1993, es "el documento de derechos humanos de mayor importancia elaborado en el último cuarto del siglo XX" (Pillay, 2013, p. 9), porque se reafirma el carácter universal, indivisible, interdependiente e interrelacionado de los derechos humanos. 
La Conferencia de Viena fue el inicio de un proceso de aprobación del Protocolo Facultativo del Pacto Internacional de Derechos Económicos, Sociales y Culturales, en vigor desde mayo de 2013.

La Declaración de Viena condena las graves y sistemáticas violaciones de los derechos humanos en todas las regiones del mundo (párrafo 29), como el genocidio y la limpieza étnica (párrafo 28); la tortura, los tratos o penas crueles, inhumanos y degradantes, ejecuciones sumarias, desapariciones, detenciones arbitrarias, racismo, discriminación racial, apartheid (párrafo 30), y ve con preocupación la cuestión de la impunidad de los autores de violaciones de los derechos humanos (párrafo 91).

Tal estado de conflicto es de interés de la comunidad internacional, sobre todo porque se transgrede la dignidad humana, fundamento de los derechos que emanan de la esencia del ser humano.

Esta declaración ha favorecido el avance de métodos y estrategias para aliviar la situación de las víctimas y prevenir violaciones futuras. En este contexto se inscribe la justicia restaurativa, puesto que esta se enfoca en las víctimas, y no solo en el victimario, como suele hacerlo la justicia penal tradicional.

El Consejo Económico y Social de las Naciones Unidas presentó un informe (abril 2002) sobre el debate acerca de la reforma del sistema de justicia penal:

Los Estados Miembros y de las organizaciones intergubernamentales y no gubernamentales, así como de los institutos que integran la red del Programa de las Naciones Unidas en materia de prevención del delito y justicia penal, sobre la conveniencia y los medios de establecer principios comunes para la aplicación de programas de justicia restaurativa en materia penal $[\mathrm{y}]$ declaración de principios básicos sobre la utilización de programas de justicia restaurativa en materia penal ... Los miembros del Grupo de Expertos sobre Justicia Restaurativa apoyaron la idea de promover medidas de justicia restaurativa en el ámbito de los sistemas de justicia penal.

Estos y otros documentos delinean la naturaleza y funcionamiento de organismos que se han ocupado de difundir la aplicación de la justicia restaurativa, incluso como auxiliar de gran importancia en situaciones críticas a consecuencia de delitos de alto impacto y generados por violencia extrema de grupos que sobrepasan la capacidad del sistema jurídico para someter a los autores de estos crímenes y evitar que se sigan cometiendo, lo que crea un gran número de víctimas, inseguridad e inestabilidad social, y a toda la humanidad, pues el daño que se hace a una víctima es un daño que se le inflige a toda la humanidad. De allí el compromiso axiológico de protección a las víctimas, consagrado en las normas internacionales de Derechos Humanos y del Derecho Internacional Humanitario.

En estos contextos surge la 'justicia transicional', que junto con la restaurativa, tienden a restablecer un ambiente de paz. La relevancia de la justicia restaurativa se evidencia al ajustarse a cualquier ambiente donde se requiera recuperar la armonía perdida por el conflicto, máxime cuando es resultado de delitos graves, como los que dan origen a la justicia transicional. 


\section{LA JUSTICIA RESTAURATIVA COMO AUXILIAR DE LA JUSTICIA TRANSICIONAL}

Según Esteban Cuya (2011), justicia transicional es el "conjunto de medidas orientadas a superar los graves daños causados en la sociedad por regímenes totalitarios o dictatoriales que en contextos de anomalía constitucional cometen violaciones a los derechos humanos contra personas o grupos de una determinada nación", de tal manera que estos regímenes o grupos se convierten en destructores de la paz'.

Las Naciones Unidas (2004, párr. 8) han definido la justicia transicional como:

Toda la variedad de procesos y mecanismos asociados con los intentos de una sociedad por resolver los problemas derivados de un pasado de abusos a gran escala, a fin de que los responsables rindan cuentas de sus actos, servir a la justicia y lograr la reconciliación.

Este problema es antiguo, pero como afirman Uprimny y Saffon (2006, p. 114), lo nuevo del enfoque actual del problema de las transiciones de la guerra a la paz es el agregado del sustantivo "justicia", de ahí que "la justicia aparece como una exigencia que cualifica de manera importante los procesos transicionales", de modo que, según estos autores, los procesos transicionales tienen por objeto cambios radicales que lleven a la paz en equilibrio con las exigencias de la justicia. La justicia transicional es algo parecido al "derecho después de la guerra"), concepto nuevo si pensamos que tradicionalmente existía el derecho a la guerra y el derecho en la guerra. En este período se discuten los derechos de las víctimas que se habían quedado en el olvido: derechos a la verdad, a la justicia y a la reparación.

Según Botero y Restrepo (2006) los procesos transicionales plantean una tensión entre los derechos de las víctimas y la necesidad de adoptar medidas que conduzcan a una transición efectiva, como conceder amnistías o indultos a los causantes de las violaciones, con el riesgo de que se deje de lado la obligación, de exigencia internacional, de reparar violaciones a los derechos humanos. Estar en períodos de transición no justifica la anulación de las obligaciones internacionales de los estados porque estas omisiones ya constituyen delitos internacionales.

1 Estas medidas se nutren de los principales instrumentos internacionales de derechos humanos como son, entre otros: la Carta de las Naciones Unidas (1945), Convención para la Prevención y Castigo del Crimen de Genocidio (1948), la Convención en contra de la Tortura y otros Tratos Crueles, Inhumanos o Degradantes, y su Protocolo Facultativo (2002), la Convención Internacional para la Eliminación de todas las Formas de Discriminación Racial (1969), los cuatro convenios de Ginebra (1945) y sus protocolos adicionales; los Principios para la Prevención Efectiva e Investigación de las Ejecuciones Extrajudiciales, Arbitrarias y Sumarias (Res. 65 ECOSOC, 14.05.1989) y su Manual (1991); la Declaración sobre la Protección de todas las Personas contra las Desapariciones Forzadas (1992), los Principios de derecho internacional reconocidos en la Carta y en el Juicio del tribunal de Nürenberg (1950), el Estándar Mínimo de Reglas para el Tratamiento de los Prisioneros (ECOSOC 13.05. 1977), la Convención Internacional para la Protección de todas las Personas de las Desapariciones Forzadas (2006). 
La guerra provocada por grupos o dictadores que no acatan el orden democrático y que no existe fuerza legal para enfrentar esta situación de violaciones graves a los derechos humanos crea un ambiente de tensión y sufrimiento, que hace necesario recurrir a métodos y estrategias que tengan eficacia para que estos grupos depongan su actitud violenta y se concierte la paz. Existe incertidumbre por la manera en que afecta el comportamiento de los actores, dentro de un conflicto armado, a las posibilidades reales de consecución de la paz y reconciliación, e incluso la conformación de un Estado de derecho, tras la finalización de las hostilidades.

La relación del derecho internacional humanitario ${ }^{2}$ con los procesos transicionales puede enfocarse desde dos momentos: antes del conflicto, en el que el Estado debe garantizar la aplicación de las normas del derecho internacional para prevenir las violaciones graves de los derechos humanos, y el momento posterior al conflicto con la obligación de poner fin a las violaciones del derecho internacional humanitario y buscar enjuiciar a quienes hayan cometido violaciones graves en conflictos armados internacionales.

El Secretario General de la ONU, en el informe ante el Consejo de Seguridad (2004, p. 4), enfatizó que

no es posible consolidar la paz en el período inmediatamente posterior al conflicto ni mantenerla a largo plazo a menos que la población confíe en que se podrá obtener la reparación de las injusticias sufridas a través de estructuras legítimas encargadas del arreglo pacífico de las controversias y la correcta administración de justicia.

La justicia restaurativa es uno de los procesos, métodos y estrategias de arreglo pacífico de controversias, por lo que se reconoce su práctica y se recomienda en los procesos transicionales.

Con las numerosas experiencias por las que ha pasado la humanidad, el derecho internacional humanitario ha fijado criterios para regir estos procesos, los que deben incluir los de esclarecimiento de la verdad, de consensos entre los actores que intervienen en el conflicto y de decisiones políticas que ayuden a restablecer la armonía social (ONU, S/2004/616).

Estos procesos se complican cuando los agresores solo están dispuestos a dejar las armas o a transitar a un régimen de orden y democracia si se acepta el olvido y el perdón de sus crímenes, por lo que es necesario construir una vía por la que se logren acuerdos políticamente viables, sin que se favorezca la impunidad ni se abandone a las víctimas. De ahí que, como afirman Uprimny y Saffon (2006), la justicia transicional es una justicia específica en contextos excepcionales por la que

2 El derecho internacional humanitario lo constituyen, principalmente, los Convenios de Ginebra y sus Protocolos adicionales que regulan las formas en que se pueden librar los conflictos armados. Protegen especialmente a las personas que no participan en las hostilidades (civiles, personal sanitario, miembros de organizaciones humanitarias) y a los que ya no pueden seguir participando en las hostilidades (heridos, enfermos, náufragos, prisioneros de guerra). https://www.icrc.org/spa/war-and-law/ treaties-customary-law/geneva-conventions/overview-geneva-conventions.htm 
se busca un punto de equilibrio entre las exigencias de la justicia y la necesidad de restablecer la paz.

Uno de los efectos más graves de los conflictos armados es ignorar a las víctimas ${ }^{3}$. En este sentido, la justicia restaurativa tiene un papel relevante en cuanto a los procesos y estrategias para que esta transición sea equilibrada, que la paz no se logre a costa de la no reparación y satisfacción de los daños a las víctimas, sino que se cree un ambiente de seguridad para que, en lo posible, se repare el daño y se reinserte a los ofensores a la vida civil sin menoscabo de los derechos de todos los involucrados.

En los delitos graves, por su naturaleza, no debe operar la prescripción cuando no existan recursos eficaces contra el delito que causó el daño. La amnistía debe tener límites; los autores de delitos graves conforme al derecho internacional no podrán beneficiarse de esta medida, ni de ninguna semejante como la clemencia o el indulto cuyo resultado sea la no reparación del daño a la víctima; en caso de que se recurra a la amnistía, esta no exime al ofensor de la reparación del daño.

El derecho de asilo y de extradición no se podrá invocar cuando haya motivos fundados para creer que son estrategias para evadir la responsabilidad de reparar el daño por la comisión de delitos graves conforme al derecho internacional. La obediencia al superior jerárquico tampoco exime de la responsabilidad generada por el delito, ni cabe alegar el desconocimiento del superior de lo que hacen sus subordinados, ni ampararse en el ejercicio de un cargo oficial para justificar la responsabilidad por hechos delictuosos.

Los derechos que deben garantizarse en los procesos de justicia transicional se refieren, sobre todo, a las víctimas: a la verdad, de acceso a la justicia, a la reparación del daño y a la garantía de no repetición. Con este objetivo, se crean comisiones de la verdad para investigar los hechos, informar a la población lo que en realidad sucedió, reconocer a las víctimas a fin de determinar la dimensión del daño y la manera de repararlo.

La justicia restaurativa opera una vez que se ha reconocido el daño causado a las comunidades, así que la justicia transicional puede auxiliarse de la justicia restaurativa para que a través del diálogo de los involucrados en el proceso se lleguen a acuerdos duraderos que resuelvan los conflictos obstructores de la paz. En el contexto de conflictos armados y en presencia de graves y extensas violaciones a los derechos humanos, crueldad y barbarie, el enfoque de la justicia transicional junto con la justicia restaurativa puede ser clave para un proceso de paz sólido y una

Conforme al principio 8 de la Resolución 60/147 (2005) de las Naciones Unidas, víctima es "toda persona que haya sufrido daños, individual o colectivamente, incluidas lesiones físicas o mentales, sufrimiento emocional, pérdidas económicas o menoscabo sustancial de sus derechos fundamentales, como consecuencia de acciones u omisiones que constituyan una violación manifiesta de las normas internacionales de derechos humanos o una violación grave del derecho internacional humanitario". Conforme al principio 15, "la reparación ha de ser proporcional a la gravedad de las violaciones y al daño sufrido". 
restauración efectiva. Desmond Tutu (2013), Nobel de la Paz 1984, afirma que la justicia verdadera no es el castigo, sino la restauración.

Se enfatiza que, en situaciones tan graves, como la violencia sistemática y masiva, delitos contra la vida y contra la dignidad del ser humano, debe matizarse la intervención restaurativa;

Los problemas deben ser manejados integralmente, pues para que la paz prospere se requiere de una cimentación profunda y sólida en la sociedad, en la que participan los gobiernos y la comunidad internacional en general, pues no hay duda de que la construcción de la paz es el requisito previo para el desarrollo económico, social y democrático de los pueblos (Huertas et al., 2016)

Por ello, los diálogos restaurativos en estos casos tendrían que construirse después de procesos penales y decisiones políticas, porque la injusticia del pasado es algo que no puede hacerse a un lado, pues las víctimas vienen de un largo olvido público que no debe repetirse, sino repararse. En la justicia transicional, los procesos restaurativos se aplican al final del juicio, cuando ya se han identificado a las víctimas y los agresores han aceptado su culpa; los procesos restaurativos no pueden paliar la culpabilidad ni desproteger a las víctimas, sino que implican acuerdos para satisfacer las necesidades de reparación, son complementarios del proceso transicional, pero de suma importancia, porque contribuyen a que se concluya en armonía y esta sea duradera.

Un caso actual de justicia transicional es el proceso de acuerdos para la terminación del conflicto armado en Colombia, en él la justicia restaurativa tiene una función importante de acuerdo con su naturaleza.

\section{EL PAPEL DE LA JUSTICIA RESTAURATIVA EN EL PROCESO DE LA JUSTICIA TRANSICIONAL EN EL CASO COLOMBIA}

Colombia y otros países del mundo han sufrido las consecuencias de la guerra, que ha dejado miles de muertos, principalmente entre la población civil. En Latinoamérica, países como Argentina y Chile han transitado de la guerra a la paz, a través de los principios de la justicia transicional; en Colombia, estos procesos se llevan para formular acuerdos de paz con grupos paramilitares y guerrilleros, como las Fuerzas Armadas Revolucionarias de Colombia-Ejército del Pueble (FARC-EP) y el Ejército de Liberación Nacional.

Según Natalio Cosoy (2016), hay tres elementos que originaron el conflicto: la tendencia a ejercer violencia desde el poder y la política; la falta de resolución en la cuestión de la propiedad de la tierra en el campo, y la falta de garantías para la pluralidad y el ejercicio de la política. Para el restablecimiento de la paz, todos los actores del conflicto deben ceder parte de sus libertades, para lo cual el concepto 
de justicia transicional se ajustaría a las necesidades específicas, respetando los preceptos de verdad, justicia y reparación.

El conflicto armado colombiano se ha extendido por más de 50 años, desde el enfrentamiento conservador-liberal desatado a partir de 1948, con el asesinato del popular candidato liberal Jorge Eliécer Gaitán. Y ha producido numerosas víctimas entre muertos, desaparecidos, desplazados, secuestrados y otros delitos que han causado sufrimientos a la población civil. Las partes enfrentadas recurrieron a la violencia con graves transgresiones a los derechos humanos de la población civil; hubo algunas negociaciones resueltas con amnistías e indultos, muy alejadas de la justicia.

La justicia transicional, con el sentido que hoy tiene, inició en 2005 con la desmovilización de los principales grupos paramilitares en cumplimiento de la Ley de Justicia y $\mathrm{Paz}^{4}$ y la creación del Grupo de Memoria Histórica que se convirtió en el Centro Nacional de Memoria Histórica.

En reconocimiento de esta tragedia nacional se acordó que el resarcimiento de las víctimas debería estar en el centro de cualquier acuerdo y que en la agenda para la terminación del conflicto debería incluirse un punto sobre las víctimas.

El Acuerdo Final es el resultado de cuatro años de diálogo que inicia con el Acuerdo General para la Terminación del Conflicto y la Construcción de una Paz Estable y Duradera (Acuerdo General) de 26 de agosto de 2012, en La Habana, Cuba, entre los líderes guerrilleros de las FARC-EP y el gobierno de Juan Manuel Santos; en el punto 5 se pacta tratar como centro del acuerdo los derechos humanos de las víctimas. Entre los acuerdos está la Declaración de Principios para la Discusión del Punto 5 de la Agenda: Víctimas (Declaración de Principios).

En noviembre de 2012, se iniciaron los diálogos de La Habana. El 24 de noviembre de 2016, Juan Manuel Santos Calderón, presidente de la República de Colombia y Timoleón Jiménez, comandante del Estado Mayor Central de las FARC-EP, firmaron el Acuerdo Final para la Terminación del Conflicto y la Construcción de una Paz Estable y Duradera (Acuerdo Final) ${ }^{5}$, después de que el 2 de octubre prevaleciera el No sobre el Sí en consulta popular. En las primeras horas después de la votación, la postura común del Gobierno colombiano y de los líderes de las FARC era mantener el diálogo y buscar una solución a este voto en contra.

Para efecto de atender los procesos que implica la justicia transicional, se creó la Jurisdicción Especial para la Paz (JEP), que es un sistema para no dejar en el olvido los crímenes de la guerra, condición necesaria para la construcción de la memoria histórica como país. Algunos responsables de las agresiones desearían que sus

4 Ley 975, publicada en el Diario Oficial 45,980 el 25 de julio de 2005: "Tiene por objeto facilitar los procesos de paz y la reincorporación individual o colectiva a la vida civil de miembros de grupos armados al margen de la ley, garantizando los derechos de las víctimas a la verdad, la justicia y la reparación" (art. 1).

5 El Acuerdo Final para la Terminación del Conflicto y la Construcción de la Paz Estable y Duradera se firmó el 24 de agosto de 2016 por el Gobierno y las FARC-EP, se sometió a plebiscito el 2 de octubre 
crímenes quedaran impunes y que la comunidad internacional ignorara una verdad que quieren ocultar a toda costa.

El Acuerdo Final para la paz en Colombia (2016, pp. 129-130), en el número 5 previó la creación de un Sistema Integral de Verdad, Justicia, Reparación y No Repetición (SIVJRNR), con el fin de lograr la mayor satisfacción posible de los derechos de las víctimas, asegurar la rendición de cuentas por lo ocurrido, garantizar la seguridad jurídica de quienes participen en él y contribuir a garantizar la convivencia, la reconciliación y la no repetición del conflicto y así construir la transición del conflicto armado a la paz. Los principios y puntos centrales en que se basa el Acuerdo sobre las víctimas son: El reconocimiento de las víctimas en su condición de ciudadanos con derechos; el reconocimiento de responsabilidad de los ofensores frente a las víctimas; la satisfacción de los derechos de las víctimas como resultado de acuerdos donde ellas intervengan; el esclarecimiento de la verdad; la reparación de las víctimas; las garantías de protección y seguridad; la garantía de no repetición; aplicación del principio de reconciliación; todo según el enfoque de derechos, en donde deben confluir todos los acuerdos de paz.

En el Acuerdo sobre las Víctimas del Conflicto se afirma que los derechos de las víctimas no son negociables, y que para el esclarecimiento de la verdad y la reparación del daño causado a personas, colectivo y territorios enteros se deben combinar mecanismos judiciales y extrajudiciales. Este documento hace especial énfasis en medidas restaurativas y reparadoras, sienta las bases para la recuperación de la confianza, para la convivencia en un escenario de construcción de paz, y para una verdadera reconciliación entre los colombianos. Así es como la justicia restaurativa auxilia en este gran proceso de reconciliación nacional. Aunque no especifica detalles sobre las estrategias restaurativas, con solo hacer referencia a ellas, da pie para utilizar los métodos de la justicia restaurativa, según los modelos que se han establecido en la práctica, con base en los principios y en la doctrina de quienes han escrito y trabajado en ella.

Las diferentes medidas y mecanismos del sistema integral deben cumplir los objetivos de satisfacción de los derechos de las víctimas, la rendición de cuentas, mediante el establecimiento de responsabilidades de todos los participantes en el conflicto que hayan causado "graves violaciones e infracciones en el contexto y en razón del conflicto armado" (Acuerdo Final, p. 128); la no repetición, mediante la aplicación de todas las medidas para impedir la revictimización, alentar el rechazo de la sociedad a la guerra y a sus efectos e impedir el surgimiento de nuevas formas de violencia; la convivencia y reconciliación, mediante la construcción de confianza en el otro a partir de las transformaciones positivas que en el seno de la sociedad se generen a los acuerdos de paz, en especial mediante el reconocimiento de las

y prevaleció el NO sobre el SÍ. Se redactó de nuevo el Acuerdo introduciendo modificaciones en atención a las demandas del pueblo colombiano, con fecha 24 de noviembre. 
víctimas y de la responsabilidad, a fin de construir un mejor futuro sobre la base de la justicia social, el respeto y la tolerancia.

Las medidas que se ajustan a los principios de justicia restaurativa para la construcción de la paz consisten en asegurar la reparación integral de las víctimas, incluyendo los derechos a la restitución, la indemnización, la rehabilitación, la satisfacción y la no repetición. Estas son características de la justicia restaurativa que ayudan a que los procesos de justicia transicional arrojen un resultado efectivo y duradero.

Estos acuerdos de paz se han celebrado con las FARC-EP, pero aún falta iniciar este proceso con el ELN, aunque recientemente se logró un acuerdo de cese al fuego temporal.

El camino hacia la consolidación de la paz es largo, pero actores y constructores de ella ya lo emprendieron y toda la comunidad internacional está pendiente de sus resultados,

Prestando especial atención a los derechos de la población, en especial de los sectores más vulnerables, como lo son las mujeres, los pueblos indígenas, niñas, niños y adolescentes, las comunidades afrodescendientes y otros grupos étnicamente diferenciados, campesinos, campesinas, personas en condición de discapacidad y los desplazados por razones del conflicto (Huertas, 2017, p. 23).

Por ello consideramos que la justicia restaurativa tiene un papel fundamental, donde quiera que se promueva la paz.

\section{LOS BENEFICIOS DE LA APLICACIÓN DE LA JUSTICIA RESTAURATIVA}

Comenta Sáez Valcárcel (2011, pp. 178-179) que la justicia restaurativa promueve la paz social, pero no anula la pena que corresponde según el derecho penal, sino que es una condición previa para abordar cualquier propuesta desde la perspectiva de este tipo de justicia. La impunidad no es un elemento de la justicia restaurativa.

En el derecho internacional, los grandes crímenes deben pasar por proceso de investigación, juicio y condena, para luego ser objeto del proceso restaurativo. No debe caber la amnistía ni la prescripción.

El proceso restaurativo implica un asunto humano y de diálogo entre las personas directamente involucradas, por lo tanto, este proceso no se da en el espacio público o colectivo, ni es una cuestión política; es encuentro y diálogo entre los protagonistas en el campo del "gran otro que es la comunidad" (Sáenz, 2011, p. 182). Ese encuentro va dirigido a comprender, no a conceder.

El derecho penal se queda en la etapa de la pena, pero relega la restauración y la reparación del daño causado en forma integral. En cambio, la justicia restaurativa 
atiende los requerimientos de estricta humanidad que el aparato judicial no está preparado para atender. El mismo encuentro entre víctima y victimario era impensable en el sistema penal; el agresor cree que con la pena paga su deuda al estado y se desvincula de la víctima; no percibe que el daño no lo causa al Estado, sino a alguien, a un ser humano en concreto. Por eso la justicia restaurativa prepara el camino para que se tome conciencia de las consecuencias del hecho delictuoso y así da lugar a que el causante pueda comprender el alcance de sus actos y se pueda generar en él el deseo de arrepentimiento y de ser perdonado. Esta actitud lleva a una auténtica reparación del daño, que posibilita que tanto la víctima como el victimario puedan reiniciar su vida normal en el grupo social al que pertenecen. La justicia restaurativa propicia que el ofensor se dé cuenta de las consecuencias del daño a una víctima determinada, que es una persona con dignidad, y que está sufriendo los efectos del delito.

La paz social parte de la paz interior del individuo; si este no supera el deseo de venganza, el odio y el rencor en quien ha sufrido un mal de difícil o imposible reparación, estos sentimientos se vuelven crónicos, se enquistan y presiden la vida personal y colectiva de manera permanente, que lejos de otorgar estabilidad para una convivencia pacífica compele a la víctima a una escalada de reafirmación en el dolor revictimizador.

El proceso restaurativo hace que se rehumanice lo deshumanizado por la agresión, puesto que esta ha degradado a las víctimas a mero objeto prescindible, y el victimario ha perdido la sensibilidad hacia el bien intrínseco que hay en sus semejantes, y su degradación lo lleva a un estadio de barbarie.

Diálogo, estrategia de la justicia restaurativa, recupera los atributos como individuo único, irrepetible e insustituible. La escucha de la palabra y de la percepción del otro hace que se capte la identidad y la dignidad del otro. La escucha atenta y respetuosa es lo opuesto al hecho violento que motiva e induce el proceso de reflexión moral.

\section{CONCLUSIONES}

1. La justicia restaurativa, como procedimiento formal para resolver conflictos de manera pacífica, es reciente. Nace cuando se centra la atención en la víctima y no solo en el victimario de hechos dañosos. Con el surgimiento de la victimología, tomaron fuerza otras formas alternativas al proceso judicial, en las cuales el papel protagónico no es el Estado, sino los participantes en el conflicto. Así, la justicia restaurativa se empezó a desarrollar, primero como experiencias exitosas y luego como una filosofía inspiradora de doctrina, métodos, procedimientos y mecanismos que se aplican para resolver no solo en conflictos derivados de delitos del orden común, sino del orden internacional.

2. La justicia restaurativa se distingue entre los medios alternativos de solución de controversias por interesar no solo el proceso, sino el fin, que es restaurar el 
tejido social dañado por un hecho. La justicia penal tradicional ha marginado a la víctima y es la justicia restaurativa la que la ubica en el centro, como protagonista, junto con el victimario y la comunidad afectada, para que juntos puedan dialogar y acordar cómo afrontar las consecuencias del hecho dañoso.

3. La justicia restaurativa ha sido desarrollada como una filosofía, una doctrina, un proceso con mecanismos y estrategias que se aplican en donde haya conflicto y se quiera resolver en forma duradera.

4. En el Derecho Internacional Público se ha recomendado como una manera de auxiliar para que se atienda a las víctimas, para evitar queden en el olvido cuando se trata de delitos del orden internacional, como el genocidio, los crímenes de guerra, de lesa humanidad y de agresión. En estos casos se recomiendo siempre y cuando se haya identificado a las víctimas, a los agresores y estén dispuestos a pactar acerca de las consecuencias del delito.

5. Particularmente, la justicia restaurativa se ha recomendado en los procesos de la justicia transicional, así llamada a la que se refiere a las condiciones en que hay que terminar un conflicto armado para transitar a un estado de paz duradero, sin que implique impunidad y olvido de las víctimas, según lo establecen las normas de derecho internacional.

6. Un ejemplo del papel de la justicia restaurativa en procesos de justicia transicional es el caso Colombia, donde se colocaron en el centro a las víctimas como condición para llegar a un acuerdo final de paz.

7. La justicia restaurativa auxilia en el proceso transicional, en cuanto está presente en los procesos para hacer efectivos los acuerdos de paz, sobre todo para proteger a las víctimas, que casi siempre son las más olvidadas.

\section{REFERENCIAS}

Barnett, R. (1977). Restitution: A New Paradigm for Criminal Justice. Ethics, 87(4), 279-291. Recuperado de http://scholarship.law.georgetown.edu/cgi/viewcontent. cgi? article $=2570 \&$ context $=$ facpub

Beristain, A. (1996). Criminología, victimología y cárceles (T. I). Bogotá.

Botero, C., y Restrepo, E. (2006). Estándares internacionales y procesos de transición en Colombia. En ¿Justicia transicional sin transición? Verdad, justicia y reparación (pp. 45-107). Bogotá: Centro de Estudios de Derecho, Justicia y Sociedad.

Britto, D. (2010). Justicia restaurativa: Reflexiones sobre la experiencia de Colombia. Loja, Ecuador: Universidad Técnica Particular de Loja.

Cosoy, N. (2016, agosto 24). ¿Por qué empezó y qué pasó en la guerra de más de 50 años que desangró a Colombia? BBC Mundo. Bogotá.

Cuarezma, S. (1996). La victimología. En Estudios básicos de derechos humanos. (T. V., pp. 295-317). San José de Costa Rica: Instituto Interamericano de Derechos Humanos. 
Cuya, E. (2011, julio). La justicia transicional en América Latina: desarrollo, aplicación y desafíos. Revista NMRZ Jurisdicción del Tribunal Criminal. Recuperado de http://www.menschenrechte.org/lang/es/strafgerichtsbarkeit/ justicia-transicional

Eglash, A. (1958). Creative restitution: Some Suggestions for Prison Rehabilitation Programs. American Journal of Correction, 20, 20-34.

Huertas, O., \& Amaya, C. (2016, diciembre). Responsabilidad penal internacional de altos dirigentes de estructuras de poder, por comisión de graves crímenes contra los derechos humanos en Colombia: Un aspecto esencial de cara al postconlicto. Justicia Juris, 12(2), 11-20.

Huertas, O. (2017). Acuerdo final para la terminación del conflicto y la construcción de una paz estable y duradera. Bogotá: Grupo Editorial Ibáñez, Unisabaneta.

Huertas, O., Manrique, F.E., Correa de M. C., Trujillo, J.S., \& Herreño, D. (2016). Retos para lograr en México la cultura de la paz y los derechos humanos. IUSTITIA, 13, 285-310.

Kelmelmajer de Carlucci, A. (2004). Justicia restaurativa: Posible respuesta para el delito cometido por personas menores de edad, Buenos Aires, Rubinzal Culzoni.

Llobet, J. (2011, enero-junio). Justicia restaurativa y garantías en la justicia penal juvenil. Revista Jurídica IUS: Doctrina, 4(6), 11-61.

Martínez, M., y Sánchez, M.P. (2011). Justicia restaurativa, mediación penal y penitenciaria: un renovado impulso. Madrid: Reus.

Naciones Unidas, Consejo Económico y Social. (2002). Informe Comisión de Prevención del Delito y Justicia Penal ( $11^{\circ}$ período de sesiones, Viena, 16 a 25 de abril de 2002. Temas 3 y 4 del programa provisional. Debate temático sobre la reforma del sistema de justicia penal: logro de la eficacia y la equidad. Reglas y normas de las Naciones Unidas en materia de prevención del delito y justicia penal). Recuperado de

https://www.unodc.org/documents/commissions/CCPCJ/CCPCJ_Sessions/ CCPCJ_11/E-CN15-2002-05/E-CN15-2002-5_S.pdf

Naciones Unidas, Consejo de Seguridad. (2004). El Estado de derecho y la justicia de transición en las sociedades que sufren o han sufrido conflictos, S/2004/616. Recuperado de http://www.un.org/es/comun/docs/?symbol=S/2004/616

Naciones Unidas, Derechos Humanos, Oficina del Alto Comisionado. (1985). Resolución 40/34. Declaración sobre los principios fundamentales de justicia para las víctimas de delitos y del abuso del poder. Recuperado de http://www. ohchr.org/SP/ProfessionalInterest/Pages/VictimsOfCrimeAndAbuseOfPower. aspx

Naciones Unidas, Derechos Humanos, Oficina del Alto Comisionado. (1993). Declaración y el Programa de Acción de Viena (DPAV). Conferencia Mundial de Derechos Humanos (CMDH). Viena. 
Naciones Unidas, Derechos Humanos, Oficina contra la Droga y el Delito. (2006). Manual sobre Programas de Justicia Restaurativa de las Naciones Unidas. Recuperado de https://www.unodc.org/documents/justice-and-prison-reform/ Manual_sobre_programas_de_justicia_restaurativa.pdf

Naciones Unidas, Derechos Humanos, Oficina del Alto Comisionado. (2013). Protocolo Facultativo del Pacto Internacional de Derechos Económicos, Sociales y Culturales, en vigor desde mayo de 2013. Recuperado de http://www. ohchr.org/SP/ProfessionalInterest/Pages/OPCESCR.aspx

Nils, C. (1977). Conflicts as Property. British Journal of Criminology, 17(1), 1-15.

Peña, Ó. (2010). Mediación y conciliación extrajudicial, medios alternos de solución de conflictos: teoría y práctica. México: Flores Editor.

Sáez, R. (2011). Notas sobre justicia restaurativa y delitos graves. Dialogando sobre 'las reflexiones' y su viabilidad. En Margarita Escamilla y María del Pilar Sánchez (coords.). Justicia restaurativa, mediación penal y penitenciaria: un renovado impulso (pp. 173-210). Madrid: Reus.

Tutu, D.M. (2013). Sin perdón no hay futuro. Buenos Aires: Hojas del Sur.

Uprimny, R. et al. (2006)¿Justicia transicional sin transición? Verdad, justicia y reparación. Bogotá: Centro de Estudios de Derecho, Justicia y Sociedad.

Van Ness, D. W., and Heetderks, K. (2015). Restoring justice: an introduction to restorative justice. London, Routledge: Taylor \& France Group.

Waller, I. (2013). Derecho para las víctimas del delito, equilibrar la justicia. México: INACIPE.

Zehr, H. (2006). El pequeño libro de la justicia restaurativa. Nueva York: GoodBooks. 